\title{
Ductile-Brittle Fatigue and Fracture Behaviour of aluminium/PMMA Bimaterial 3PB Specimens
}

\author{
G. Shatil ${ }^{1}$ and A. Saimoto ${ }^{2}$ \\ ${ }^{1}$ Structural Design Integrity Group, UWE, Bristol BS16 1QY, UK, g.shatil@uwe.ac.uk \\ ${ }^{2}$ Solid Mechanics Group, Nagasaki University, Nagasaki 8528521, Japan, \\ s-aki@net.nagasaki-u.ac.jp
}

\begin{abstract}
Fracture toughness and fatigue crack growth tests and numerical simulations on $3 P B$ specimens were carried out to study the fracture behaviour for a crack lying perpendicular to the interface in a ductile/brittle bimaterial. Polymethylmethacrylate Acrylic (PMMA) and aluminium alloy 2024 T531 were joined together using epoxy resin. A precrack was introduced into the ductile material and tests were carried out to obtain fracture toughness and fatigue properties. The body force method was used to simulate the experimental stress intensity $K_{1}$ cracking behaviour under monotonic and cyclic loads. It was found that the bimaterial fatigue crack growth rate is higher than that for monolithic aluminium 2024 but lower than the rate for a monolithic PMMA material. This agreed with the trend for the stress intensity results and it was in agreement with the numerical analysis. The initial ductile Mode 1 aluminium stable cracking appear to 'jump' the interface and continued under fracture modes 1 and 2 in the PMMA material until final failure.
\end{abstract}

\section{INTRODUCTION}

Fracture near interface of bimaterial is common in many industrial applications. In particularly, fracture near the interface has been investigated in the application of medical replacements, functionally graded materials, the coating industry, and in various pressure vessels applications including large gas containers and nuclear pressure vessels [1-5]. The type of fracture investigated requires a definition of the type of bimaterials, for example elastic-elastic or elastic-plastic fracture and brittle or ductile fracture. There are different ways to join the materials together, for example bonding, welding and heat fusion or friction welding. Previous fracture investigation considered different monolithic materials and different joint methods with different crack orientation. The majority of work was carried out to estimate fracture in parallel to the materials interface under an increased normal load.

Several workers have studied the theoretical fracture of bimaterial cracks perpendicular to the interface, including elastic-elastic materials [1], and elastic-plastic materials [2-5]. Numerical simulations have been carried out using finite element 
analysis to obtain elastic-plastic fracture properties that include J-resistance [3], Q resistance and COD [4] and also the local approach to fracture [2].

This investigation re-examined bimaterial ductile-brittle cracking behaviour where the monolithic material properties were very different in both, the elastic-elastic and elastic-plastic regions. The experimental programme consisted of fracture perpendicular to the interface under cyclic and static load of 3 point bend specimens (3PB). The numerical investigation employed the Body Force Method (BFM, [6-8]) and an elasticplastic finite element model. The results presented in this paper summarised an examination of cracks emanated from the ductile material (aluminium alloy 2024 T531), and grow through the interface to the brittle material (PMMA) until final fracture.

\section{MATERIALS AND EXPERIMENTS}

The 3PB bimaterial PMMA/Al2024 specimen's geometry and loading is shown in Figure 1 and the specimen's nominal mechanical properties are given in Table 1 . The two materials were joined at the interface by using a commercial 24 hours curing time epoxy bond, after carefully polishing the interface surfaces.

A 3mm wide notch was machined into the aluminium side of the specimens with a triangular notched tip that was located $4 \mathrm{~mm}$ from the bottom edge. To obtain sharp crack tip the specimens were fatigue precracked to initial cracks of between 1.4 and $2 \mathrm{~mm}$. The fatigue to failure tension bending tests were carried out using an Instron $20 \mathrm{kN}$ hydraulic axial test rig and a specially designed bending fixture. Crack growth was recorded optically and measured with a travelling microscope. The maximum fatigue load range was $0.4 \mathrm{kN}$ and the specimen's fractured surface was examined after each test.

Table 1. Mechanical properties

\begin{tabular}{|c|c|c|c|}
\hline Material & $\begin{array}{c}\text { Yield stress } \\
(\mathrm{MPa})\end{array}$ & $\begin{array}{c}\text { Young Modulus E } \\
(\mathrm{GPa})\end{array}$ & $\begin{array}{c}\text { Poisson ratio } \\
\text { v }\end{array}$ \\
\hline PMMA & 87 & 3.3 & 0.3 \\
\hline Al 2024 T351 & 350 & 73 & 0.35 \\
\hline
\end{tabular}

The failed specimens are depicted in Figure 2. For specimens 1 and 2 a load range of $0.2 \mathrm{kN}$ was applied, having precracks of $1.4 \mathrm{~mm}$ and $2.9 \mathrm{~mm}$ respectively. Specimen 1 crack growth in the aluminium was very small during the majority of the life with an increase in crack tip plastic zone up to final failure that occur by a through crack in the PMMA (after about $10^{6}$ cycles). Specimen 2 (with a longer precrack) involved a slow (about $10^{-6} \mathrm{~mm} /$ cycles) and stable cracking of the alluminum and fast final fracture of both materials. For specimens 3 and 4 a higher load range of $0.4 \mathrm{kN}$ was used and the crack growth rate in the aluminium during these tests was stable at about $10^{-4}$ 
$\mathrm{mm} /$ cycles. The failure in these two specimens was also due to failure of both materials simultaneously.

In specimens 1 and 2 the fracture crack path was perpendicular to the interface in both materials, along the precrack direction, Figures 2a and 2b. The crack path for specimens 3 and 4 was primarily along the precrack direction (perpendicular to interface) in the aluminium specimen and initially perpendicular and then approximately $45^{\circ}$ to the interface in the PMMA material, Figures $2 \mathrm{c}$ and $2 \mathrm{~d}$. These results were further analysed and discussed later.

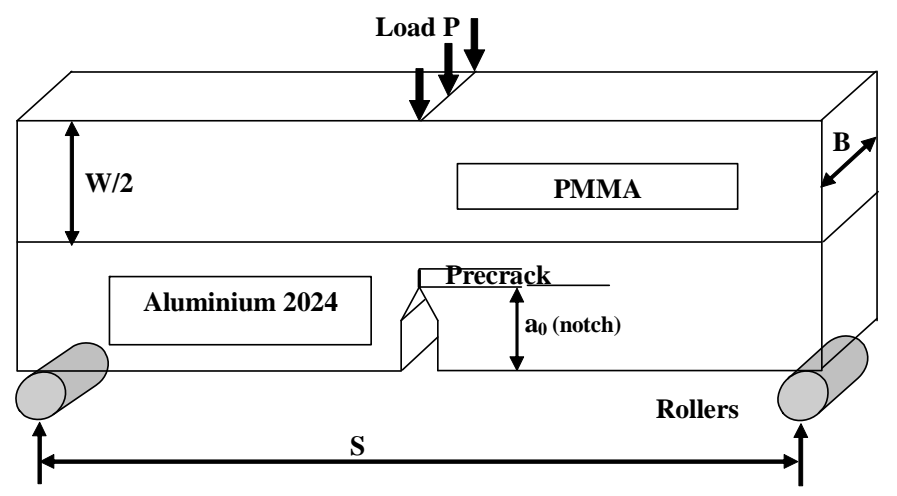

Figure 1. Specimen geometry and loading.
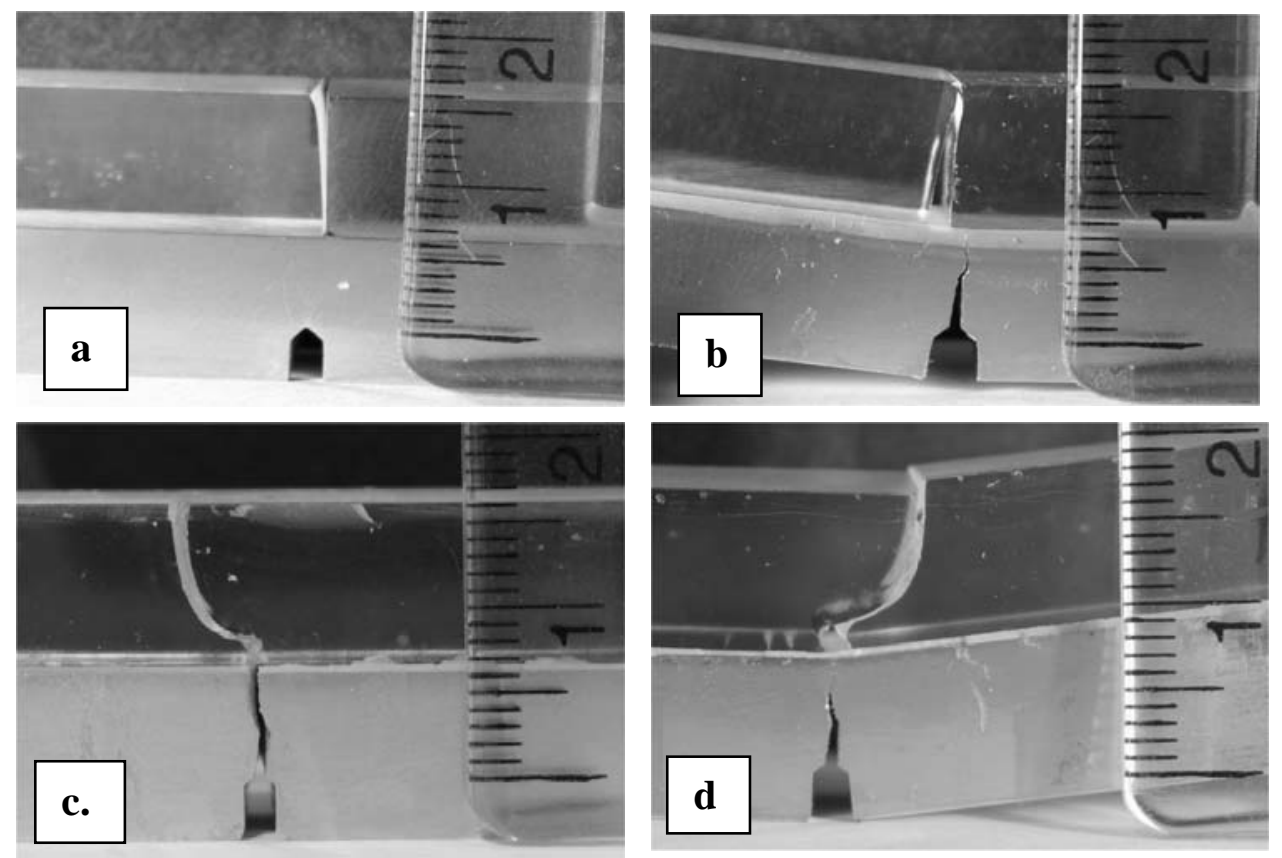

Figure 2. Bimaterial fatigue fractured specimens: a. Specimen 1, crack arrest, PMMA fracture; b. Specimen 2, fast failure in both materials; c. Specimen 3, stable fracture in both materials; d. Specimen 4, PMMA fractured while aluminium not fully cracked. 


\section{NUMERICAL ANALYSIS}

In order to evaluate the SIF values of a crack in the bimaterial 3PB specimens, the body force method (BFM) was used. The body force method (BFM) was initially proposed by Nisitani in 1967 [6-7] as a general elastic technique for the solution of stress field near notches and cracks. It has since developed further and was applied to solve numerous elastic stress problems and used in various engineering data handbooks. Since the 1990's a versatile BFM computer code was developed and applied to complex fracture problems [8].

The numerical solution of the stress intensity factors (SIFs) for the bimaterial specimen's perpendicular to interface fracture, under elastic mode I and assuming plane strain and perfect interface bonding, is shown in Figure 3. This solution is compared to SIF solution of monolithic homogenous material [9]. Two scenarios were considered; in one scenario the PMMA is upper and the aluminium is lower positioned during 3PB tests and in the second the PMMA lower and the aluminium upper.

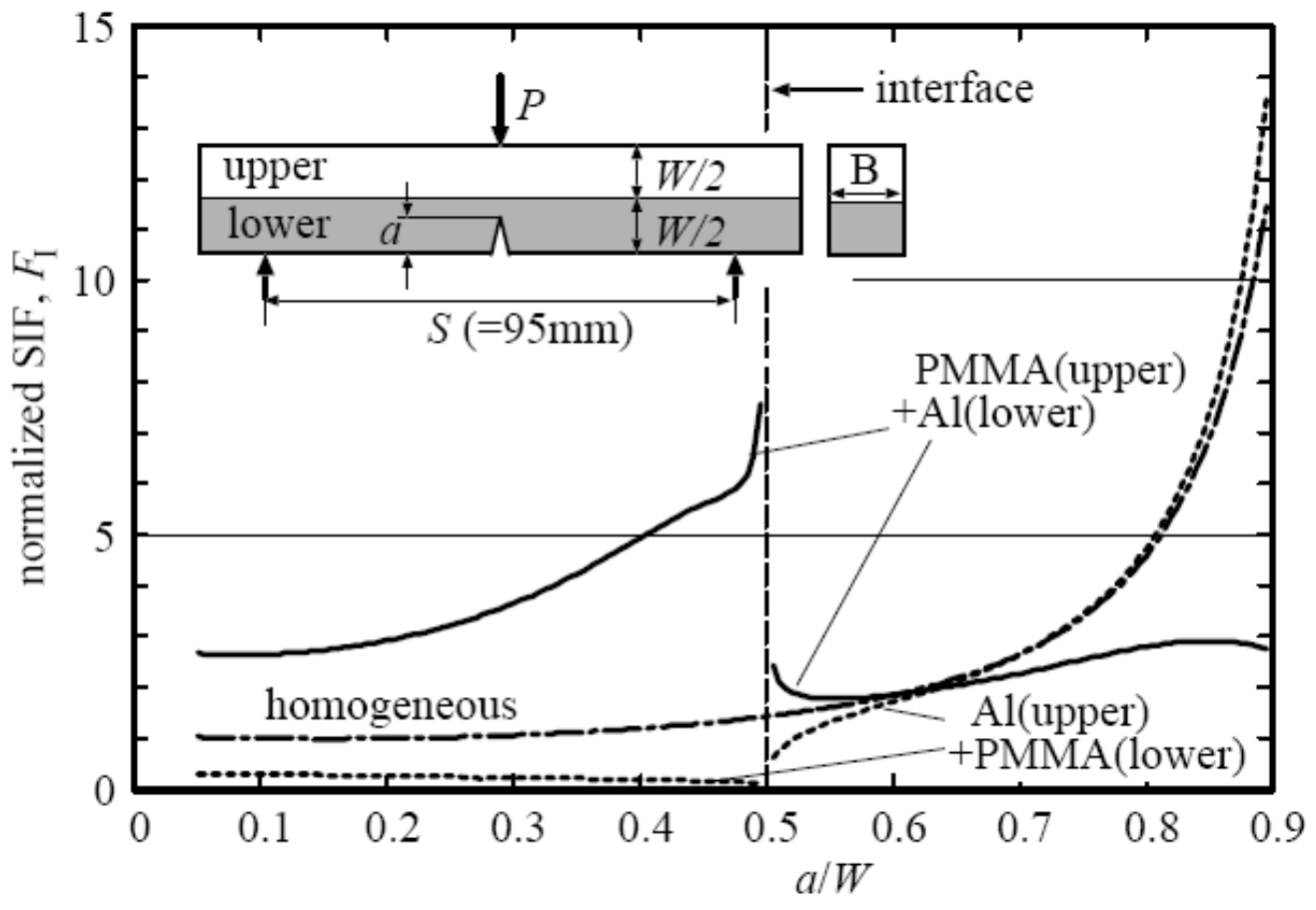

Figure 3. Numerical normalized elastic SIF solutions of the bimaterial cracking. The normalised SIF $F_{I}=K_{I} \times 2 B W^{2} / 3 P S \sqrt{\pi a}$ is plotted vs. the normalized crack length $a / W(S / W=4.75, B / W=0.5)$.

It can be seen that in general, when the crack initiate inside the ductile material (PMMA upper/Al lower) the values of SIF are larger than for the case of the homogeneous material and vice versa. It is also demonstrated that in the case of the PMMA upper/Al lower specimens, the SIF solution consists of large discontinuity when the crack tip approaches and crosses the interface. A much smaller discontinuity appears 
for the Al upper/ PMMA lower case. These numerical values of the bimatrial SIF 3PB tests where used in the fatigue crack growth analysis by assuming that $\Delta \mathrm{K}$ is equal to the $\mathrm{K}_{1 \max } \mathrm{SIF}$ solution under pure bending constant amplitude loads.

Figure 4 is showing the stress distribution for PMMA upper/Al lower around the crack tip using a normalised crack of $a / W=0.4$, which relates to crack approaches the interface. In this Figure, the normal stress in the longitudinal direction $\left(\sigma_{\mathrm{x}}\right)$ and the lateral direction $\left(\sigma_{\mathrm{y}}\right)$ are illustrated as contour maps. The interface is assumed to be perfectly bonded, and hence $\sigma_{\mathrm{y}}$ is shown continues across the interface while $\sigma_{\mathrm{x}}$ is discontinues. Since the crack tip approaches the interface, the value of $\sigma_{\mathrm{x}}$ at the point just above the interface becomes compressive. This compressive stress may turn into a positive residual stress when unloading occurs during the fatigue test and therefore, this could lead to a crack initiation inside the PMMA (upper) region. In other words, a highly compressive stress just upper of the interface may trigger a "crack jump" as observed in the experiments.
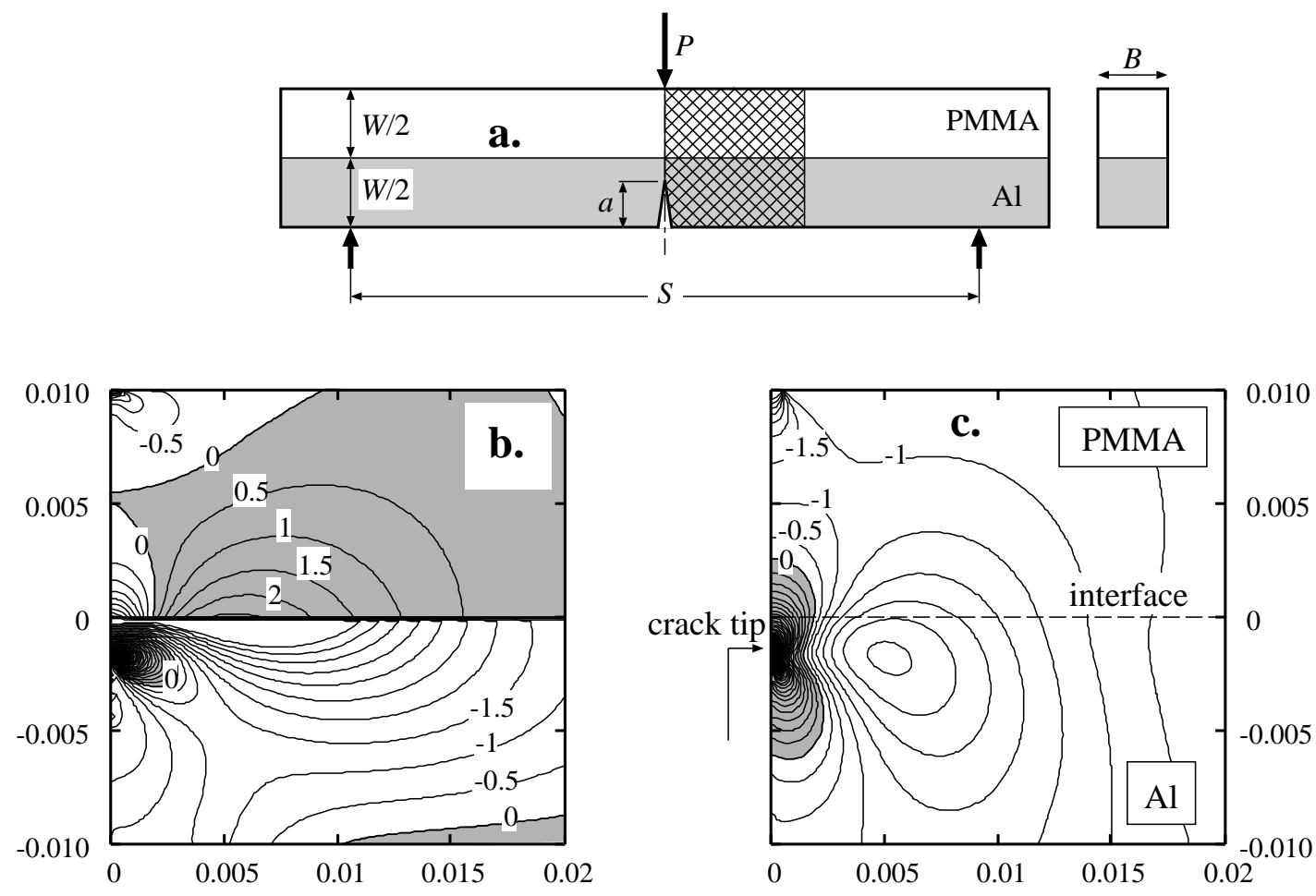

Figure 4. Distribution of stresses due to perpendicular crack ( $a / W=0.4$ ) approaching the bimaterial interface; a. Illustration of specimen where the hatching area represents the modelled area; b. Contours of $\sigma_{x} \times 2 B W^{2} / 3 P S$ and; c. Contours of $\sigma_{y} \times 2 B W^{2} / 3 P S$. (Grey region represents positive stress). 


\section{RESULTS AND ANALYSIS}

Results from the fatigue cracking tests are shown in Figure 5. The crack length vs. number of cycles in the last stage of the tests obtained from specimens 3 and 4 is shown in Figure 5a. The slow crack growth plateau is shown for the majority of the life until final stage of fast cracking to failure. The shorter life of specimen 4 was due to the longer initial crack of $3.3 \mathrm{~mm}$ compared with initial carck of $1.7 \mathrm{~mm}$ for specimen 3 .
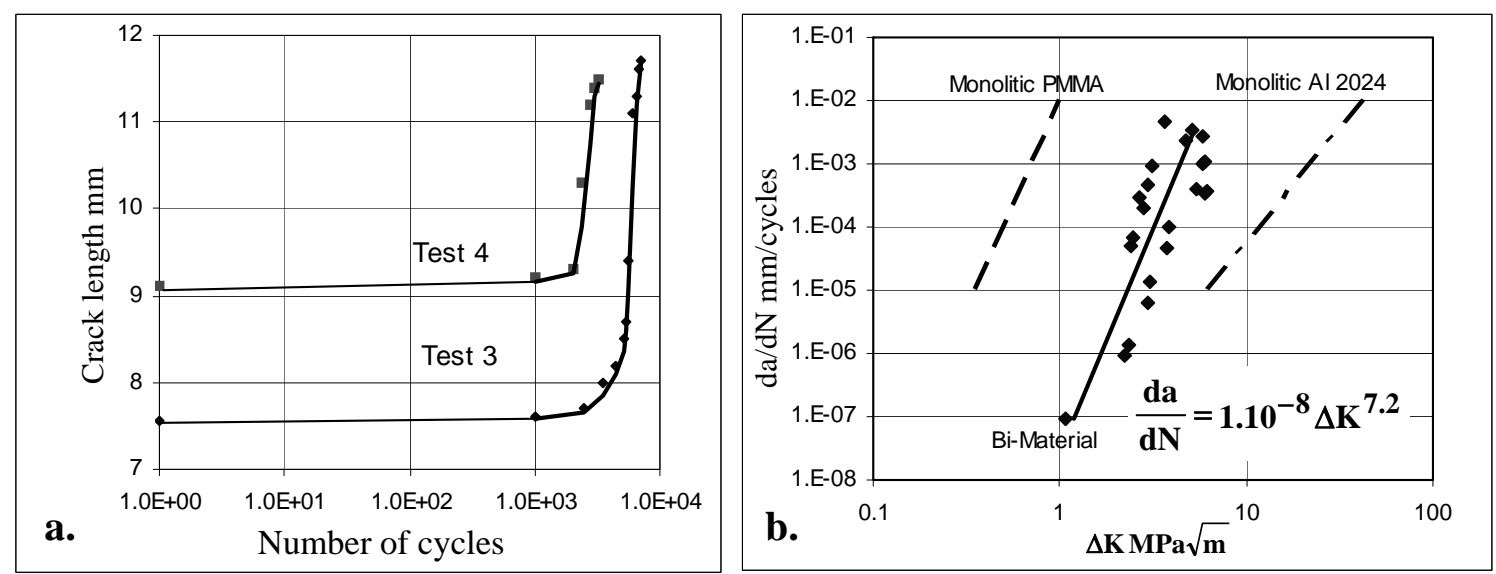

Figure 5. Experimental results. a. Crack growth vs. number of cycles to failure in specimens 3 and 4; b. Bimaterial fatigue crack growth results and the monolithic materials fatigue generic crack growth curves.

Stress intensity factors (SIFS) for each of the test results were obtained from the numerical simulations and used together with the measured $\mathrm{da} / \mathrm{dN}$ to obtain the relationship between the stress intensity range and the rate of crack growth per cycle. The results from the bimaterial tests for crack that intiated in the ductile material are shown in Figure 5b. These results are compared with results from generic monolithic PMMA and aluminium Al2024. The bimaterial fatigue results in Figure 5b indicate that in the case of the initial crack in the aluminium material, fatigue crack growth rate is higher than that for the generic aluminium material and lower than that for the PMMA. These experimental results are in agreement with the analytical BFM simulation in Figure 3 where lower SIFS values for particular cracks were obtained in the case of cracking from the aluminium side. An approximated values for the bimaterial fatigue crack growth $\mathrm{c}$ and $\mathrm{m}$ constants used in the Paris-Erdogen relationship, are also shown in Figure 5b.

Interestingly, in Figures 5a and 5b the phase in which the crack is passing through the interface from the aluminium to the PMMA is indistinguishable. The fracture of the PMMA occurred at the last 5-10\% of the life of the specimens where crack growth was relatively fast. It was observed that initial cracking of the PMMA occurred prior to complete fracture of the aluminium and hence the crack 'jumped' over the interface. 
The overall fatigue performance of the bimaterial was dominated by the additional constrain of the aluminium by the PMMA which decreases the rate of cracking in comparison to the monolithic aluminium. This behaviour was related to an increase in the fracture toughness of the bimaterial in comparison to the monolithic materials.

Similar behaviour was predicted numerically by Sigamura et al [5] where an interface perpendicular crack was investigated assuming ferritic-austenetic steel bimaterial. It was demonstrated that the crack tip is 'shielded' from the remote loads when it approaches the interface from the ductile material. Depending on the driving force at the crack tip, the crack could be arrested in the ductile material. This could explain the cracking behaviour in Specimen 1, where an increase of crack tip plasticity was observed in the aluminium during the specimen's life with a very little crack advance and until a fast failure occurred in the PMMA material.

\section{DISCUSSION}

Assuming that a 'crack jump' from the aluminium to the PMMA over the interface is caused by residual tension, it is possible to estimate the crack path by inverting the numerical loading direction. Figure 6 (right) shows a crack path simulated under this assumption. The numerical crack path is shown to be very similar to the experimental crack path in Figure 6 (left). This could explain why Mode 2 fracture was observed in the PMMA material specimens 3 and 4.
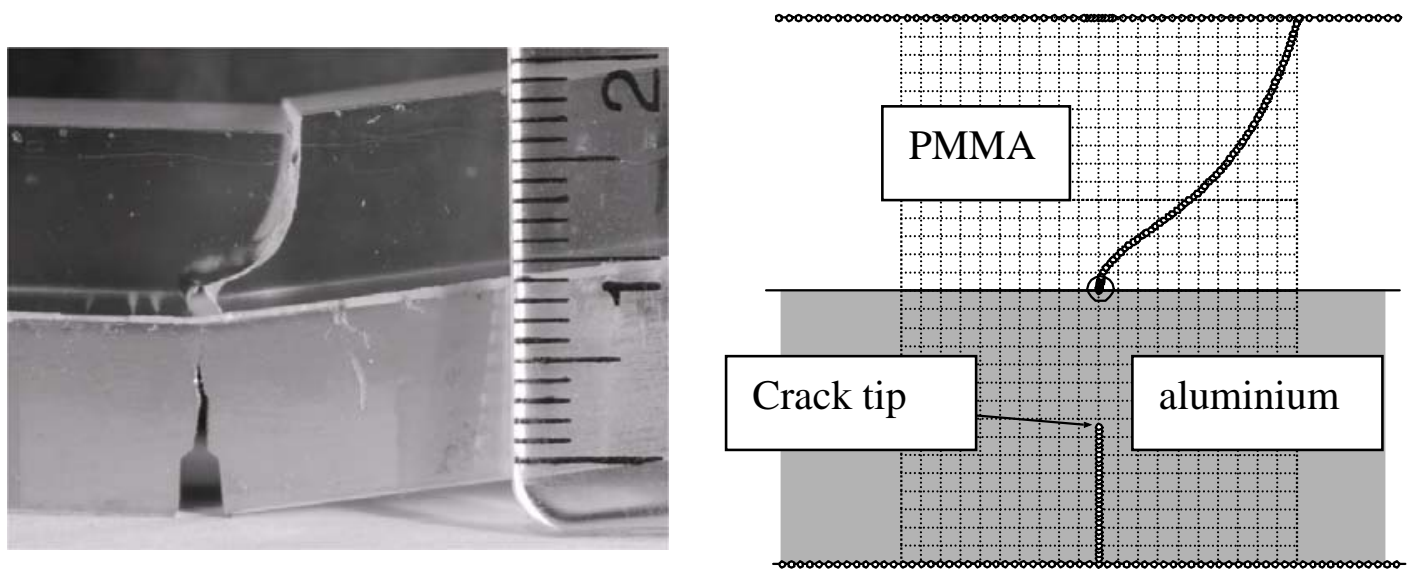

Figure 6. Experimental (left) and numerical (right) crack path in the bimaterial specimens under cyclic load and stable crack growth.

The deformation behaviour of the bimaterial specimens was investigated using simulation and test results. It was found that the elastic crack opening displacement is about 10 times larger than that of the homogeneous specimen. This was partly attributed to the increase in stiffness of the bimaterial in comparison to the aluminium. However, 
more work is currently under way to estimate the fracture by using Elastic Plastic Finite Element analysis and initial results were comparable with the BFM simulation.

\section{CONCLUDING COMMENTS}

Facture resistance behaviour of ductile/brittle bimaterial appeared to be somewhere in between the behaviour of the monolithic materials for crack emanates from the ductile material and is perpendicular to the interface. This behaviour has been observed experimentally for cyclic and monotonic loading conditions and was confirmed in the analytical calculations using the body force method and is due to additional resistance and constrained of the brittle material that affected the ductile material fracture.

Stable crack growth region appeared in the ductile material until the crack approached the interface and continued in much faster rate of about an order of a magnitude in the brittle material. The crack path was generally under fracture Mode 1 apart from the transition period where it appeared to follow Mode 2 in the PMMA material. This may have been due to the geometry and reversed loading used in the experimental programme that introduced compressive stresses near the interface.

\section{REFERNCES}

1. Shah Q.H., Hommah H., Liyas M.H. and Ismail A.F. (2005) J. Appl. Sciences. 3, 476-481.

2. Kim, A.S., Besson, J. and Pineau, A. (1998) J. Solid and Structs, 36, 1845-1864.

3. McCormack B.A.O., Prendergast P.J., and O’Dwyer B. (1999). J Fat Fract Eng Mat Strcts, 22, pp.33-40.

4. Lund P.G.,; Evans A G and McMeeking R. M. (1989) J. Appl. Mech. (Trans. ASME). 56, pp. 77-82.

5. Sugimura Y., Lim P.G., Shih C.F. and Suresh S., (1995) Acta Metallurgica, 4, pp. 1157-1169.

6. Nisitani H. (1968), Bull. Japan Soc. Mech. Engrs., Vol. 11-43, pp.15-23.

7. Nisitani H. (1978), In: Mechanics of Fracture, Vol. 5, pp.1-68, Sih G.C. (ed).

8. Nisitani H; Teranishi T; Saimoto A; Fukuyama K., (2000), Key Engineering Materials, vols. $183-187$, pt. 1, pp. 553-558.

9. Strawley J.E. (1976) Int J Fract Mech. Pp. 475-476. 